\title{
A New Fossil Anthropoid Skull from South Africa
}

\author{
By Dr. R. Broom, F.R.S., Transvaal Museum, Pretoria
}

$\mathrm{I}^{\mathrm{T}}$

is nearly twelve years ago since Prof. R. A. Dart startled the world by the announcement of the discovery of a new type of fossil anthropoid found in a limestone cave at Taungs in Bechuanaland, South Africa. The specimen consists of most of the brain cast and the practically perfect face of a very young ape. The functional teeth are all of the milk set, though the first upper and lower molars have cut the gum but do not yet meet. Though the ape was only very young, Dart estimated the cranial capacity at more than 500 c.c., and considered that in an adult it might exceed 700 c.c. $\mathrm{He}$ believed that this little fossil ape is not very closely allied to either the chimpanzee or the gorilla, and that it is probably

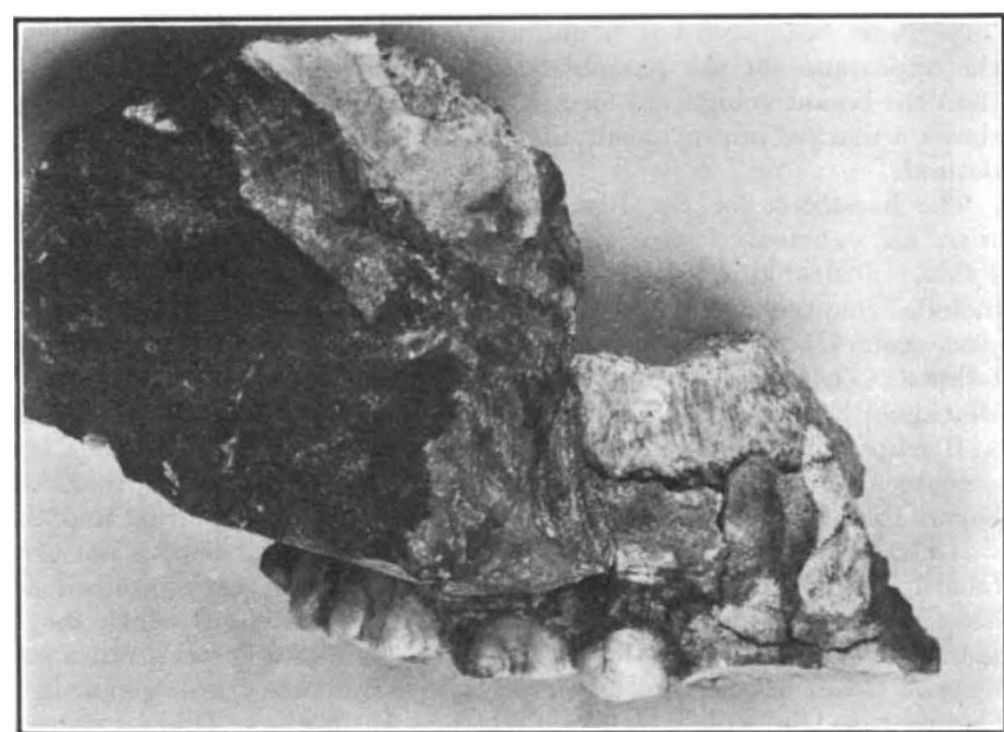

FIG. 2. Side view of right upper maxilla with the 2nd premolar and the 1st and 2nd molars. Parts of the roots of the canine and 1st premolar are shown. Slightly enlarged. Photograph by Mr. Herbert Lang. nearer to the ape from which man has been descended and thus to be practically the long sought for missing link.

Many European and American men of science considered that Dart had made a mistake, and that if he had had a series of young chimpanzee

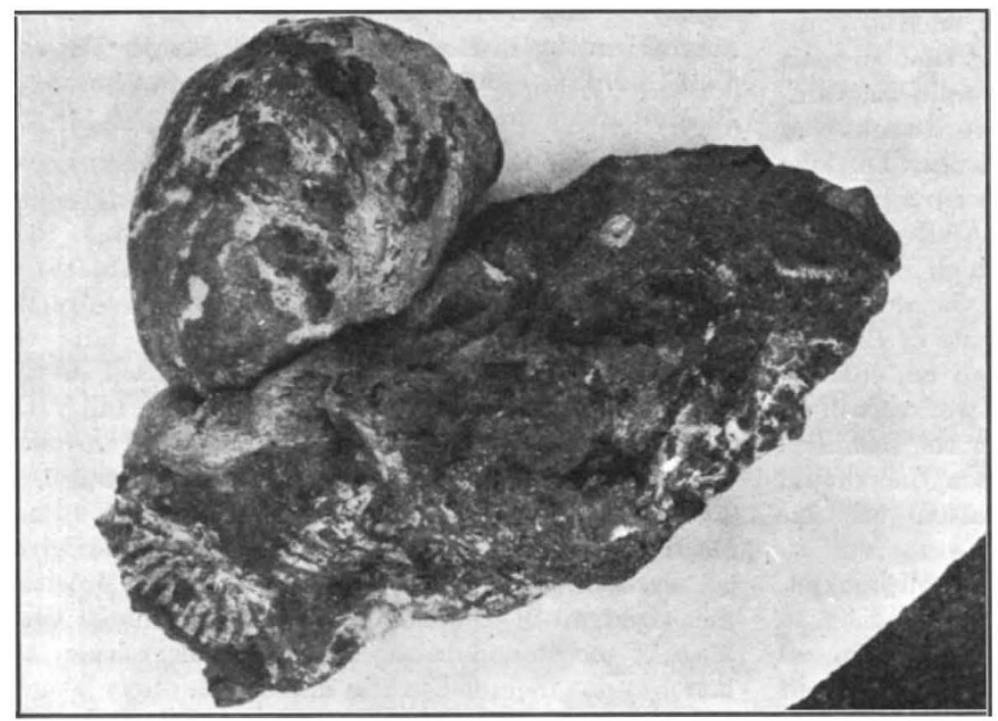

FIG. 1. Half side view of the brain cast resting on the imperfect base. The brow ridges are shown with parts of the frontal sinuses exposed. Part of the left cheek bone is also shown. About $\frac{1}{8}$ natural size. Photograph by Mr. Herbert Lang. skulls for comparison he would have recognized that the Taungs ape is only a variety of chimpanzee. When after some years the lower jaw was detached from the upper and the crowns of the teeth could be examined fully, it was found that the milk teeth are not in the least like those of either the chimpanzee or gorilla, and that they agree entirely with those of man, though larger. In the gorilla and chimpanzee the first upper milk molars have each two cusps . in man and in Australopithecus there are three well-marked cusps in each. In the first lower milk molar of the gorilla. there is only one large cusp; in the chimpanzee there is one large cusp and a second rudimentary cusp. In man and in Australopithecus there are four well-developed cusps.

I have constantly maintained since $\mathrm{I}$ first examined the skull in 1925 that Dart was essentially right in holding Australopithecus is not closely allied to either the gorilla or chimpanzee, and is on or near the line by which man has arisen. 
I do not know what is at present the opinion in Europe as to where Australopithecus ought to be placed. Gregory of New York regards it as fairly near to the origin of the human line ; and Romer of Harvard says it is "clearly not a chimpanzee or a gorilla". But the most important thing to do seemed to be to get an adult skull. For the last

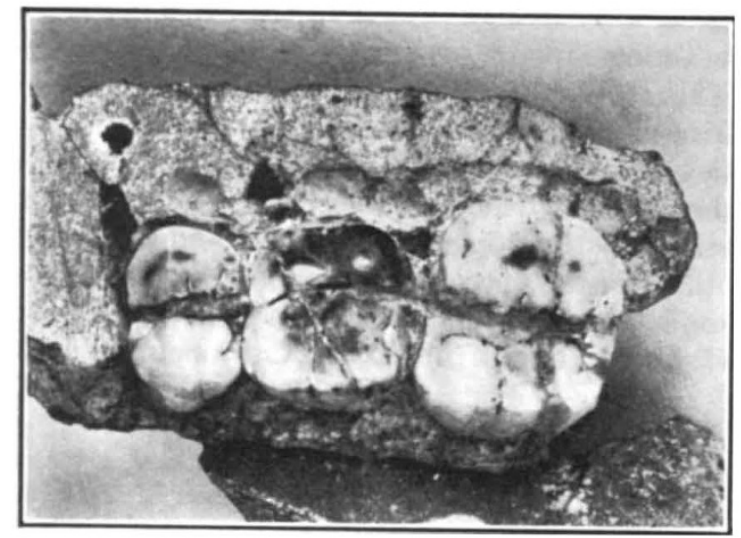

Fia. 3. Crowns of right upper 2nd premolar and 1st and 2nd molars. $x$ about 9 . Photograph by Mr. Herbert Lang.

three months, I have been busy working on the bone breccia of the limestone caves of the Transvaal largely in the hope of getting either a new 'missing link' or a type of primitive man. I have so far found no trace of man, though $I$ have discovered more than a dozen new species of fossil mammals, a number of which belong to new genera.

Two weeks ago [Dr. Broom's covering letter is dated August 8.-Ed.], when visiting the caves at Sterkfontein near Krugersdorp, Mr. G. W. Barlow, the very understanding manager of the lime works there and on whom I had impressed the importance of keeping his eyes open for a Taungs ape, handed me the brain cast of what appeared to be a large anthropoid (Fig. 1). It had been blasted out of the side of the cave a couple of days before. A search for some hours failed to find any other part of the skull, but we found the cast of the top of the head in the cave wall. A more extensive search on the following day with a large party of workers resulted in the discovery of most of the base of the skull, with the upper part of the face (Fig. 2). In the same matrix was found the detached right maxilla with three teeth, and the third upper molar was also found, though detached. The lower part of the face had been removed before fossilization; and so far no mandible or lower teeth have been found, though parts may yet be discovered in a mass of crushed and broken bones near the side of the head. As the bones are very friable, no attempt has as yet been made to remove them from the much harder matrix.
Much of the cranial vault has been destroyed by the blast, but a large part of each parietal is preserved and a considerable part of the occiput. Unfortunately, the back of the brain cast is missing, and though the base of the skull is complete to the back of the foramen magnum, the contacts of the occipital fragment are lost.

The brain cast is perfect in its anterior two thirds. When complete it probably measured in length about $120 \mathrm{~mm}$. and in breadth about $90 \mathrm{~mm}$. ; and the brain capacity was probably about 600 c.c. The skull probably measured from the glabella to the occiput about $145 \mathrm{~mm}$., and the greatest parietal width was probably about $96 \mathrm{~mm}$.

The brow ridges are moderately developed and there are fairly large frontal sinuses. The auditory meatus is $73 \mathrm{~mm}$. behind the brow. It will be possible to make out much of the detailed structure of the base of the skull, but as yet no attempt has been made to clean it out as the bone is very friable and the investigation cannot be done in a hurry.

In the maxilla there are three well preserved teeth, the 2nd premolar and the lst and 2nd molars (Fig. 3). The canine and 1st premolar are lost but the sockets are preserved. The canine has been relatively small. At its base it probably measured about $10 \mathrm{~mm}$. by $8 \mathrm{~mm}$. The 2 nd premolar is somewhat worn. Its crown measured $11 \mathrm{~mm}$. by $9 \mathrm{~mm}$. Its pattern is well seen in Fig. 3 .

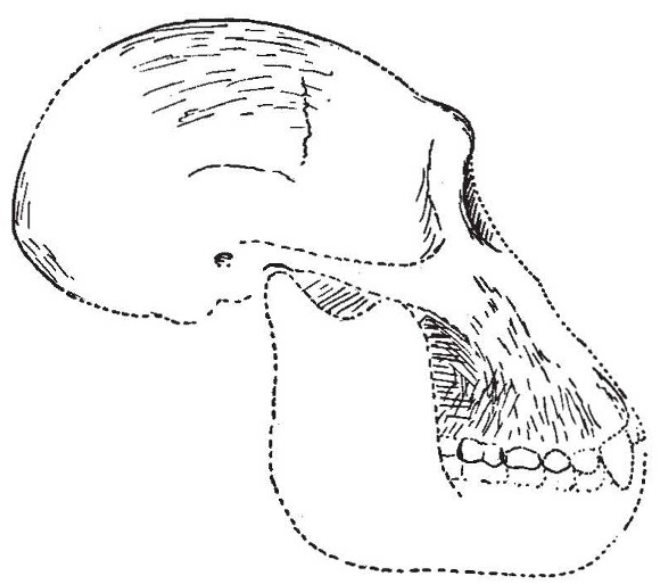

FIG. 4. Attempted restoration of skull of Australopithecus transvaalensis Broom. t $\frac{1}{8}$ natural size.

Sufficient of the cranium is preserved to show its shape with certainty. Most of the right maxilla is preserved, but it is not in contact with the upper part of the skull, and there is thus a little doubt as to the relations.

The 1st molar is moderately large. Anteroposteriorly it measures $12 \mathrm{~mm}$. and transversely $13 \mathrm{~mm}$. It is of the typical Dryopithecid pattern -four well-developed cusps with a little posterior ridge and a well-marked posterior fovea. The tooth agrees fairly closely with that of the first molar of Dryopithecus rhenanus. The 2 nd molar is 
exceptionally large. It measures $14.5 \mathrm{~mm}$. in antero-posterior length and is $16 \mathrm{~mm}$. across. It has four large cusps with a well-marked posterior fovea. The 3rd molar has been detached from the bone but it is preserved in perfect condition and unworn. It has three well-developed cusps, but the hypocone is relatively small owing to the invasion of the large fovea. The tooth measures antero-posteriorly $13.7 \mathrm{~mm}$. and transversely $15.5 \mathrm{~mm}$. The crown in this unworn condition is extremely wrinkled.

The whole premolar and molar series measures $59 \mathrm{~mm}$.

This newly-found primate probably agrees fairly closely with the Taungs ape, but the only parts that we can compare are the brain casts and the lst upper molars. The brain cast of the new form is considerably wider, especially in the frontal region, and the molar teeth differ in a number of important details. Further, the associated animals found at Taungs are all different from those found at Sterkfontein. I think the Taungs deposit will probably prove to be Lower or Middle Pleistocene, while the Sterkfontein deposit is most probably Upper Pleistocene. I therefore think it advisable to place the new form in a distinct species, though provisionally it may be put in the same genus as the Taungs ape.

This discovery shows that we had in South Africa during Pleistocene times large non-forest living anthropoids-not very closely allied to either the chimpanzee or the gorilla but showing distinct relationships to the Miocene and especially to the Pliocene species of Dryopithecus. They also show a number of typical human characters not met with in any of the living anthropoids.

\section{The Control of the Circulation of the Blood*}

\section{By Prof. R. J. S. McDowall}

\section{VaRiations In the Activity of the HeaRT}

Tr. HE heart is not like an ordinary pump which sucks fluid from one tube and pushes it into another. The veins are so thin that any degree of suction would cause them to close. The heart is filled by the pressure of the blood which reaches it during the time it is relaxed, and adjusts the force of its stroke to the amount of blood in it at the beginning of contraction. The more blood reaching it, the more it pumps out, within limits. This is made possible by the fact that the force with which the heart contracts is increased if the heart muscle is stretched.

The heart can also change its rate. In the past it has been usual to describe the heart as being under two sets of controlling nerves, one the sympathetic, which when stimulated makes the heart go fast, and the other the vagus, which makes the heart go slower. Now we know that this is only part of the story. The evidence is almost complete that the heart is really under the control of two sets of reflexes which have this function. The difference between these statements is that the second involves an afferent pathway to the central nervous system, for the sympathetic and the vagus are constantly carrying down impulses to the heart, and if they are cut off the heart goes slow or fast as the case may be. In the case of the sympathetic, we do not know accurately as yet the exact source of the afferent impulses, but

* From the presidential address to Section I (Physiology) of the British Association, delivered at Blackpool on September 11. the fact that stimulation of any sensory nerves causes cardiac acceleration suggests that the source is stimulation from the outside world. This is not necessarily conscious, for it has been shown that a sound may accelerate the heart of a person who is asleep, but during waking hours the higher centres undoubtedly play a part in the acceleration. I shall refer to this further in relation to the vasomotor centre. In the case of the inhibitory impulses which slow the heart, the source of the afferent impulses is known. These arise from certain sensitıve regions within the circulation itself. These are situated in the left side of the heart, the arch of the aorta and the carotid sinuses, which are small dilatations at the bifurcation of the common carotid artery in the neck.

When exercise is taken, two changes occur: the sympathetic accelerator impulses increase and in particular the vagus impulses are reduced. The evidence for this rests on the effect of exercise and other procedures on the heart rate before and after section of the vagi, and with and without the sympathetic. It has been shown, for example, that if the vagus nerves have been cut the increase of the heart rate is, during the exercise, not nearly so great as it was before they were cut. It is not possible for me to discuss here how the change is brought about, except to say that it is in part due to the action of the higher centres and to a rise of venous pressure. The increased temperature of the blood and adrenaline liberated by the suprarenal gland enhance the effect of the nervous changes. 